\title{
Investigating the effect of nitrogen on the structural and tribo-mechanical behavior of vanadium nitride thin films deposited using R.F. magnetron sputtering
}

\author{
Linda Aissani ${ }^{1,2}$, Mamoun Fellah ${ }^{3}$, Ablel Hakim Chadli ${ }^{4}$, Mohammed Abdul Samad ${ }^{5,6}$, \\ Abderrahmane Cheriet $^{7}$, Faiza Salhi ${ }^{1}$, Corinne Nouveau ${ }^{8}$, Sabine Weiß ${ }^{9}$, Aleksei Obrosov ${ }^{9, *}$ (1), and \\ Akram Alhussein $^{10}$ \\ ${ }^{1}$ Mater Sciences Department, Abbes Laghrour-Khenchela University, P.O 1252, 40004 Khenchela, Algeria \\ ${ }^{2}$ Active Components and Materials Laboratory, Larbi BEN M'HIDIUniversity, 04000 Oum El Bouaghi, Algeria \\ ${ }^{3}$ Department of Mechanical Engineering, AbbesLaghrour- Khenchela University, P.O 1252, 40004 Khenchela, Algeria \\ ${ }^{4}$ Molecular Chemistry and Environment Laboratory, University of Biskra, Biskra, Algeria \\ ${ }^{5}$ Department of Mechanical Engineering, King Fahd University of Petroleum and Minerals, Dhahran 31261, Saudi Arabia \\ ${ }^{6}$ Interdisciplinary Research Centre for Advanced Materials, King Fahd University of Petroleum and Minerals, Dhahran 31261, Saudi \\ Arabia \\ ${ }^{7}$ Laboratory of Studies and development of the Semiconducting and Dielectric Materials, Laghouat University, Laghouat, Algeria \\ ${ }^{8}$ LABOMAP, Arts Et Metiers Institute of Technology, HESAM Université, 71250 Cluny, France \\ ${ }^{9}$ Department of Physical Metallurgy and Materials Technology, Brandenburg University of Technology, 03044 Cottbus, Germany \\ ${ }^{10}$ LASMIS, Technological Pole of South Champagne, University of Technology of Troyes, 26 Lavoisier rd, 52800 Nogent, France
}

Received: 18 May 2021

Accepted: 24 July 2021

Published online:

3 August 2021

(C) The Author(s) 2021

\begin{abstract}
Magnetron sputtering is one of the most commonly used deposition techniques, which has received considerable attention in industrial applications. In particular, owing to its compatibility with conventional fabrication processes, it can produce and fabricate high-quality dense thin films of a wide range of materials. In the present study, nitrogen $(\mathrm{N})$ was combined with pure vanadium in order to form binary nitride to improve its mechanical and tribological performance. To evaluate the influence of nitrogen on the structure of the as-deposited vanadium nitride (VN) coatings, the following techniques were used: XPS, XRD, SEM, AFM and optical profilometry. The residual stresses were determined by the curvature method using Stoney's formula. The hardness and Young's modulus were obtained by nanoindentation measurements. The friction behavior and wear characteristics of the films were evaluated by using a ball-ondisk tribometer. The obtained results showed that the $N / V$ ratio increased with increasing the $\mathrm{N}_{2}$ flow rate while the deposition rate decreased. The preferred orientation was changed from (200) to (111) as the $\mathrm{N}_{2}$ flow rate increased with
\end{abstract}

Handling Editor: Catalin Croitoru.

Address correspondence to E-mail: aleksei.obrosov@b-tu.de 
the presence of $\mathrm{V}-\mathrm{N}$ and $\mathrm{V}-\mathrm{O}$ binding energies as confirmed by XPS analysis. The nitrogen addition resulted in a columnar morphology and a fine structure with fine surface roughness. The $\mathrm{VN}$ thin film containing 49.5 at.\% of nitrogen showed the best performance: highest mechanical properties (hardness $=25$ $\mathrm{GPa})$, lowest friction coefficient $(\mu=0.37)$ and lowest wear rate $\left(\mathrm{W}_{\mathrm{s}-}\right.$ $=2.72 \times 10^{-5} \mathrm{~mm}^{3} \mathrm{~N}^{-1} \mathrm{~m}^{-1}$ ). A good correlation between the film microstructure, crystallite size, residual stress and mechanical and tribological properties was observed.

\section{Introduction}

The hard phases corresponding to transition metal nitrides are capable of retaining their mechanical properties such as strength and hardness under extreme conditions, because of which, they have been receiving considerable attention in the recent past [1-3]. Vanadium nitride (VN) is one such transition metal nitride, which has found its way in a wide variety of applications in many industrial fields, owing to their excellent properties such as high hardness and wear resistance, good electrical and thermal conductivity [4, 5], good catalytic activity, and excellent thermal stability [6-8].,. VN particularly in the form of thin film is extensively used in industrial devices requiring high performance, corrosion resistance and improved abrasion resistance in microelectronics, superconductors and sometimes as decorative coatings. However, they are widely used as hard coatings for cutting tools to improve their service life and performance [9-14].

The fcc-VN compound has six-coordinate nitrogen $(\mathrm{N})$ and eight-coordinate $\mathrm{N}$ in its structure and the crystal structure of high-pressure $\mathrm{V}_{2} \mathrm{~N}$ phase has a hexagonal structure in which $\mathrm{N}$ atoms occupy the octahedral interstitial sites [10]. Hofer et al. [11] reported a rapid thermal processing of vanadium layers in pure nitrogen at elevated temperatures, and their electron diffraction patterns revealed different phases: fcc-VN structure was identified around $1100{ }^{\circ} \mathrm{C}$ and the hexagonal structure $\mathrm{V}_{2} \mathrm{~N}$ was found at $900{ }^{\circ} \mathrm{C}$. In an another study, XRD measurements of $\mathrm{VN}$ samples showed that the films deposited at $150{ }^{\circ} \mathrm{C}$ at lower nitrogen gas flow, exhibit significantly higher hardness as compared to that of the transition metal nitrides phase with $\mathrm{NaCl}$ structure [12].

It is well-known that the deposition parameters such as the substrate temperature, deposition time, substrate bias and nitrogen flow rate influence the structural, mechanical and tribological performance of the produced VN thin films [2]. Chu et al. [15] showed that the film morphology, phase transformation and properties of sputtered $\mathrm{VN}$ thin films were related to the film microstructural changes, which are controlled by the deposition parameters such as nitrogen partial pressure, substrate bias and target power. A mixture of crystalline $\mathrm{hcp}-\mathrm{V}_{2} \mathrm{~N}$ and fcc-VN phases was obtained at about 50 and 60 at.\% of vanadium (V). Maximum hardness of $29 \mathrm{GPa}$ was found for the $\mathrm{V}_{2} \mathrm{~N}_{\mathrm{x}}$ phase produced at a nitrogen pressure of $1.33 \mathrm{~Pa}$. Suszko et al. [16] reported that the preferred orientation was changed with nitrogen pressure from (311) through (111) to (200) planes parallel to the substrate surface. The preferential (200) orientation was observed at the highest nitrogen partial pressure $\left(\mathrm{Ar} / \mathrm{N}_{2}=0.35 / 1.2 \mathrm{~Pa}\right)$.

Caicedo et al. [17]. produced VN films from a metallic $\mathrm{V}$ target sputtered in a gaseous atmosphere of $\left(\mathrm{N}_{2}+\mathrm{Ar}\right)$ mixture at different D.C. negative bias voltages. Nanoindentation measurements showed that increasing the bias voltage from 0 to $-150 \mathrm{~V}$ enhanced the film hardness and elastic modulus up to $20 \mathrm{GPa}(\mathrm{H})$ and $221 \mathrm{GPa}(\mathrm{E})$, respectively. A preferential orientation of fcc-VN (200) plane was observed. Moreover, the VN coating deposited at the highest D.C. bias voltage $(-150 \mathrm{~V})$ presented a greater corrosion rate than that obtained for the film deposited without substrate polarization. Qiu et al. [18]. reported that increasing the nitrogen content influenced the density of coatings, their maximum hardness (22.9 GPa) and residual stresses (-1.62 GPa) generated during the deposition process.

Ina previous work, the effect of film thickness and $\left(\mathrm{Ar}-\mathrm{N}_{2}\right.$ ) plasma gas on the structure and performance of $\mathrm{VN}$ coatings deposited by R.F. magnetron sputtering was studied. At $10 \%$ of $\mathrm{N}_{2}$, the presence of the hcp $-V_{2} \mathrm{~N}$ phase was observed. Then, the structure 
changed from single hcp- $\mathrm{V}_{2} \mathrm{~N}$ to combination of hcp$\mathrm{V}_{2} \mathrm{~N}$ and fcc-VN when the nitrogen increased up to $20 \%$. The thicker films containing a high amount of nitrogen were slightly denser as compared to the thinner ones presenting rough surface and a columnar structure. The highest hardness of $26.2 \mathrm{GPa}$ was obtained for the VN film deposited under $20 \%$ of $\mathrm{N}_{2}$, which is correlated with its dense structure and stoichiometric composition. Furthermore, a lower friction coefficient of about 0.4 was found for the thickest film of $2.5 \mu \mathrm{m}$ [21].

However, limited reports are available investigating the effect of chemical compositions and bonding structure on the tribo-mechanical properties of $\mathrm{V}-\mathrm{N}$ [17-21]. Moreover, most of the previous studies have reported only the hardness of VN (13 GPa) phase [19], while the mechanical properties of other $\mathrm{V}-\mathrm{N}$ compounds are still rarely reported due to the difficulty of preparing the samples with different stoichiometries. Therefore, a comprehensive investigation on the influence of the deposition parameters on the structure as well as tribo-mechanical properties is required, in order to suitably adjust the properties of $\mathrm{V}-\mathrm{N}$ films. Hence, the current study is focused on the microstructure evaluation and relates the chemical compositions and bonding structure to mechanical properties, adhesion and tribological performance of $\mathrm{VN}$ films. By controlling the $\mathrm{N}_{2}$ flow rate, a series of $\mathrm{VN}$ thin films with various compositions and morphologies were prepared. The effect of nitrogen content on microstructure, mechanical and tribological performance of $\mathrm{VN}$ thin films is explored in detail. In contrast to the reports in the literature, results of this work showed a significant dependence of film behavior on its microstructure and confirmed a substantial enhancement in friction and wear characteristics of XC100 steel coated by $\mathrm{VN}$ thin films that could be used in a wide range of industrial applications.

\section{Experimental details}

\section{Substrate preparation}

XC100 steel substrates ( $15 \mathrm{~mm} \times 3 \mathrm{~mm}$ ) were grinded by abrasive papers and polished with a diamond suspension to obtain a RMS roughness of about $30 \mathrm{~nm}$. Steel substrates and Si (100) wafers $(10 \mathrm{~mm} \times 10 \mathrm{~mm} \times 480 \mu \mathrm{m}) \quad$ were ultrasonically cleaned with acetone and ethanol for $10 \mathrm{~min}$, rinsed with deionized water and dried with compressed air. The as-deposited films on the XC100 substrates were used to investigate the microstructure, mechanical and tribological properties, while coatings on Si (100) wafers were employed to observe the surface topography, cross-sectional morphologies as well as to measure the residual stress.

\section{Film deposition}

VN thin films were deposited by reactive R.F. magnetron sputtering (NORDIKO type 3500, $13.56 \mathrm{MHz}$ ) from circular $\mathrm{V}$ target $(99.9 \%$ purity, $\varnothing 10.6 \mathrm{~cm}$ ). Detailed description of sputtering process is presented in our earlier study [21]. Target to substrate distance was kept constant at $80 \mathrm{~mm}$ for all depositions. The deposition temperature in the process chamber was about $150{ }^{\circ} \mathrm{C}$. Prior to deposition, the chamber was evacuated to a low pressure of $6 \times 10^{-4} \mathrm{~Pa}$. The total sputtering $\left(\mathrm{Ar}+\mathrm{N}_{2}\right)$ gas flow rate was $100 \mathrm{sccm}$, which maintained the working pressure at $0.4 \mathrm{~Pa}$. In order to remove the surface oxides and to etch the surface, the substrates were initially cleaned using an argon flow rate of $80 \mathrm{sccm}$, a pressure of $0.4 \mathrm{~Pa}$ and a bias voltage of $-200 \mathrm{~V}$. Vanadium target was cleaned in Ar using a voltage of $700 \mathrm{~V}$ for $10 \mathrm{~min}$ to remove the surface oxides and contaminations.

In order to enhance the $\mathrm{VN}$ film-to-substrate adhesion, a pure vanadium interlayer of $\sim 60 \mathrm{~nm}$ was deposited on the substrates prior to the actual film deposition by applying a power of $250 \mathrm{~W}$ to the vanadium target for 5 min under a pure argon gas atmosphere with a flow rate of $50 \mathrm{sccm}$.

VN thin films were deposited by simultaneously injecting $\mathrm{Ar}$ and $\mathrm{N}_{2}$ into the chamber for $120 \mathrm{~min}$ and the sputtering RF power (bias voltage) for $\mathrm{V}$ target was kept at $550 \mathrm{~W}$ (-900 V). Five different configurations of gas mixtures were used with varying nitrogen flow rates of 5, 10, 15, 20 and $25 \mathrm{sccm}$.

\section{Film characterization techniques}

VN thin films were deposited on the Si (100) wafers for physicochemical characterizations, determination of residual stresses, and observation of the surface morphology and cross section of the films by SEM and topography by AFM. However, the VN thin films deposited on the XC100 steel substrates were used for 
the analysis by $\mathrm{X}$-ray diffraction, nanoindentation measurements and for tribological tests.

The crystalline structure phases of the as-deposited films were identified by X-ray diffraction (XRD, type Bruker D8t) with Co-K $\alpha$ radiation $(\lambda=0.178 \mathrm{~nm})$ at $40 \mathrm{kV}$ and $35 \mathrm{~mA}$. The film spectra were obtained using $(\theta-2 \theta)$ angle diffraction by varying $2 \theta$ between $25^{\circ}$ and $80^{\circ}$ with a $0.02^{\circ}$ scan step. In order to determine the preferred orientation degree, texture coefficient $\left(T_{c}\right)$ was calculated using the following formula [22]:

$\boldsymbol{T}_{\boldsymbol{c}}(\mathbf{h k \mathbf { k }})=\frac{\frac{\mathbf{I}(\mathbf{h k l})}{\mathbf{I}_{\text {bulk }}(\mathbf{h k l})}}{\frac{1}{\mathbf{N}} \sum_{\frac{\mathbf{I}}{\mathbf{I}_{0}(\mathbf{h k l} \mathbf{l} \mathbf{l})}}}$

where $\mathrm{I}(\mathrm{hkl})$ film is the normalized integral intensity of the (hkl) diffraction peak, $\mathrm{I}(\mathrm{hkl})_{\text {bulk }}$ is the integral intensity of the bulk material peak, $\mathrm{N}$ is the number of consider peaks.

The ratio of (hkl) orientation (\%) was calculated using the following equation:

$\mathrm{I}(\mathrm{hkl}) / \mathrm{I}(\mathrm{hkl})_{\text {bulk }}$

where I(hkl)film is the normalized intensity of the (hkl) diffraction peak, which is equal to the top the (hkl) peak on the XRD pattern; I(hkl)bulk is the integral intensity of the bulk material peak after correction.

The crystallite size (D) of the VN thin films was calculated using Scherrer's formula [23]:

$\mathbf{D}=\frac{0.9 \lambda}{\boldsymbol{\beta} \cos \boldsymbol{\theta}}$

where 0.9 is a dimensionless shape factor, $\lambda$ the wavelength of the $\mathrm{CO}_{\mathrm{K} \alpha}$ incidence, $\beta$ the width at halfmaximum of the diffraction peak and $\theta$ the Bragg's angle of VN phase.

The lattice strains of the (111) VN plane were calculated using the following equation:

$\varepsilon=\frac{\Delta \mathbf{a}}{\mathbf{a}_{\text {bulk }}}$

where $\varepsilon$ is the lattice strain in the $a$ axis direction, $\Delta \mathbf{a}=\left(\mathbf{a}_{\text {coating }}-\mathbf{a}_{\text {bulk }}\right), \mathrm{a}_{\text {coating }}$ and $\mathrm{a}_{\text {bulk }}$ present the cubic VN phase.

The ratio of (hkl) orientation (\%) was calculated using the following equation:

$\mathrm{I}(\mathrm{hkl})_{\text {film }} / \mathrm{I}(\mathrm{hkl})_{\text {bulk }}$

where $\mathrm{I}(\mathrm{hkl})_{\text {film }}$ is the normalized intensity of the (hkl) diffraction peak, which is equal to the intensity of (hkl) peak on the XRD pattern; $\mathrm{I}(\mathrm{hkl})_{\text {bulk }}$ is the integral intensity of the bulk material peak after correction.

The binding energy of the $\mathrm{VN}$ thin films was determined by X-ray Photoelectron Spectroscopy (XPS, Riber SIA 100 spectrometer) with a nonmonochromatic X-ray source $\left(\mathrm{Al}_{\mathrm{K} \alpha}\right.$ line of $\left.1486.6 \mathrm{eV}\right)$, an applied power of $300 \mathrm{~W}$ and a vacuum pressure of $4 \times 10^{-8} \mathrm{~Pa}$. The calibration was done using the line of $\mathrm{C} 1 \mathrm{~s}$ of about $284.5 \mathrm{eV}$ and a full width at halfmaximum (FWHM) of $1.1 \mathrm{eV}$, which was absorbed on the sample surface [24]. In the XPS analysis, C1s has made a spectacular referencing due to the fact that thin C contamination layers, in the form of socalled adventitious carbon are present on all surfaces that have been previously exposed to the atmosphere $[4,24]$. Hence, calibrating the XPS scale to the C1s peak set at $284.5 \mathrm{eV}$ is justified and may lead to physical results, like a zero density of states at the Fermi level especially for conducting samples such as metals, where charging effects can definitely be excluded [24].The V2p, O1 and N1s spectra were obtained by Casa XPS software analysis [25].

Cross-sectional images of the films deposited on $\mathrm{Si}$ (100) wafers were observed by a Scanning Electron Microscope (SEM, JEOL JSM-6400F). The elemental analysis of the films was determined by Energy Dispersive Spectroscopy (EDS, Oxford INCA x-act). The surface roughness and three-dimensional topographies of the films were characterized by an Atomic Force Microscopy (AFM, Type 100, APE research) in a contact mode by applying a constant force of $0.032 \mathrm{~N} / \mathrm{m}$ and scanning an area of $3 \times 3$ $\mu \mathrm{m}^{2}$.

The residual stresses of the $\mathrm{VN}$ thin films were calculated using the following Stoney's equation [26]:

$\boldsymbol{\sigma}=\frac{\mathbf{E}_{\mathbf{s}}}{6\left(1-\mathbf{v}_{\mathbf{s}}\right)} \times \frac{\mathbf{t}_{\mathbf{s}}^{2}}{\mathbf{t}_{\mathbf{f}}}\left(\frac{1}{\mathbf{R}}-\frac{1}{\mathbf{R}_{0}}\right)$

where $E_{s}$ is the substrate Young's modulus, $v_{s}$ the substrate Poisson's ratio, $t_{s}$ the substrate thickness, $t_{f}$ the film thickness, $R_{0}$ the curvature radius of sample before deposition and $\mathrm{R}$ the curvature radius of the coated sample measured using an optical profilometer.

The mechanical properties of the films (hardness and Young's modulus) were obtained using a nanoindenter equipped with a Berkovich diamond tip (Nanoindenter MTS-XP) by applying a load of 50 $\mathrm{mN}$. The mechanical properties were calculated 
using the Oliver-Pharr method [27]. The hardness values were determined from the average of 5 indentations. The maximum indenter penetration was limited to $10 \%$ of the total film thickness in order to avoid the influence of substrate and surface roughness. The friction and wear performances of the as-deposited films were tested by a ball-on-disk tribometer using a $100 \mathrm{Cr} 6$ ball as a counterpart $(\Phi=6 \mathrm{~mm})$. The tests were carried out applying a normal load of $2 \mathrm{~N}$ with a sliding speed of $0.05 \mathrm{~m} / \mathrm{s}$ for $20 \mathrm{~min}$. The friction coefficient curves were recorded by software associated with the data acquisition. The worn wear tracks, depth and wear rates were determined by means of an optical 3D profilometer (VEECO, Wyko-NT 1100) [2]. The worn surfaces were analyzed by using SEM and EDS.

\section{Results and discussion}

\section{Structural analysis}

Table 1 presents the elemental composition of films deposited under different nitrogen flow rates. It is clearly observed that nitrogen content in the VN thin films significantly increased from 15.4 to 51.3 at.\% with increasing $\mathrm{N}_{2}$ flow rate from 5 to $25 \mathrm{sccm}$. N/V ratio increased from 0.18 to 1.10 and the deposition rate gradually decreased from $10.8 \mathrm{~nm} / \mathrm{min}$ to $7.5 \mathrm{~nm} / \mathrm{min}$ (Table 1). Since the deposition rate is strongly dependent on the number of $\mathrm{N}$ and $\mathrm{V}$ atoms arriving upon the substrate surface, low deposition rate was due to the reduction of $\mathrm{V}$ concentration in the $\mathrm{VN}$ thin film that is confirmed by the increasing of $\mathrm{N} / \mathrm{V}$ ratio [28]. This is attributed to the target contamination, which is consistent with the results reported by Huang et al. [22] showing a similar decrease in the $\mathrm{Ti}$ content in TiN thin films as a function of increasing nitrogen flow rate. The presence of oxygen in a low percentage (2-2.8 at.\%) is probably due to the moderate vacuum and the presence of residual oxygen in the deposition chamber [21].

The XPS core-level spectra in the V2p, N1s and O1s regions, for the $\mathrm{VN}$ thin films deposited under 10 and $20 \mathrm{sccm}$ of nitrogen, are shown in Fig. 1. XPS spectra indicated that there are not only $\mathrm{V}-\mathrm{V}$ and $\mathrm{N}-\mathrm{V}$ binding energies but also $\mathrm{V}-\mathrm{O}$. At $10 \mathrm{sccm}$, the $\mathrm{V} 2 \mathrm{p}_{3 / 2}$ has two peaks (Fig. 1a). The first peak is centered at the $\mathrm{VN}$ binding energy of $514.62 \mathrm{eV}$ [2] while the second peak is centered at $514.82 \mathrm{eV}$ corresponding to the $\mathrm{V}_{2} \mathrm{~N}$ binding energy [29]. The $\mathrm{V} 2 \mathrm{p}_{1 / 2}$ peak is centered at $522.42 \mathrm{eV}$ corresponding to $\mathrm{VN}$ and $\mathrm{V}_{2} \mathrm{~N}$ phases, respectively [2, 29]. For the N1s (Fig. 1b), the dominant binding energy was around $396.25 \mathrm{eV}$ corresponding to $\mathrm{V}-\mathrm{N}$ bonds of $\mathrm{VN}$ and $\mathrm{V}_{2} \mathrm{~N}$ [30].

The difference in the binding energies $(\triangle \mathrm{BE})$ between the $\mathrm{N} 1 \mathrm{~s} \pm \mathrm{Vp}$ levels was also calculated. The $\Delta \mathrm{BE}$ values between the N1s $\pm \mathrm{V} 2 \mathrm{p}$ levels were found to be decreasing with increasing nitrogen content according to the position of their V2p and $\mathrm{N}$ $1 \mathrm{~s}$ levels. The chemical shift of the core levels can be attributed to the change in the charge distribution providing an indication of the degree of ionicity and covalency of the bonding [31].

The O1s spectrum becomes wider and less intense, with one peak at about $530.49 \mathrm{eV}$ consistent with $\mathrm{V}-$ $\mathrm{O}$ binding energy (Fig. 1c) [33]. At $20 \mathrm{sccm}$, the V2 $\mathrm{p}_{3}$ /
Table 1 Elemental compositions and structural properties of $\mathrm{VN}$ thin films

\begin{tabular}{llllll}
\hline $\mathrm{N}_{2}$ flow rate (sccm) & 5 & 10 & 15 & 20 & 25 \\
\hline $\mathrm{N}($ at.\%) & 15.4 & 25.8 & 41.2 & 49.5 & 51.3 \\
$\mathrm{~V}$ (at.\%) & 82.6 & 72.0 & 56.0 & 48.5 & 46.6 \\
$\mathrm{O}($ at.\%) & 2 & 2.2 & 2.8 & 2 & 2.1 \\
$\mathrm{~N} / \mathrm{V}$ ratio & 0.18 & 0.36 & 0.73 & 1.01 & 1.10 \\
Thickness (nm) & 1300 & 1240 & 1150 & 960 & 900 \\
Deposition rate $(\mathrm{nm} / \mathrm{min})$ & 10.8 & 10.3 & 9.6 & 8.0 & 7.5 \\
Lattice Parameter, a (nm) & 0.4122 & 0.4131 & 0.4137 & 0.4139 & 0.4141 \\
Lattice Strain $\left(\varepsilon \cdot 10^{-5}\right)$ & -442 & -197 & -499 & 11 & 52 \\
Crystallite size (nm) & 31 & 29 & 28 & 25 & 26 \\
Ratio of $(111)$ orientation $(\%)$ & 10 & 22 & 50 & 75 & 50 \\
Ratio of $(200)$ orientation $(\%)$ & 90 & 78 & 50 & 25 & 50 \\
\hline
\end{tabular}

Deposition conditions: R.F. power $=550 \mathrm{~W}$, Voltage $=-900 \mathrm{~V},\left(\mathrm{P}_{\mathrm{Ar}}+\mathrm{P}_{\mathrm{N} 2}\right)=0.4 \mathrm{~Pa}$, Temperature $\approx$ $150{ }^{\circ} \mathrm{C}$, Deposition time $=120 \mathrm{~min}$ 

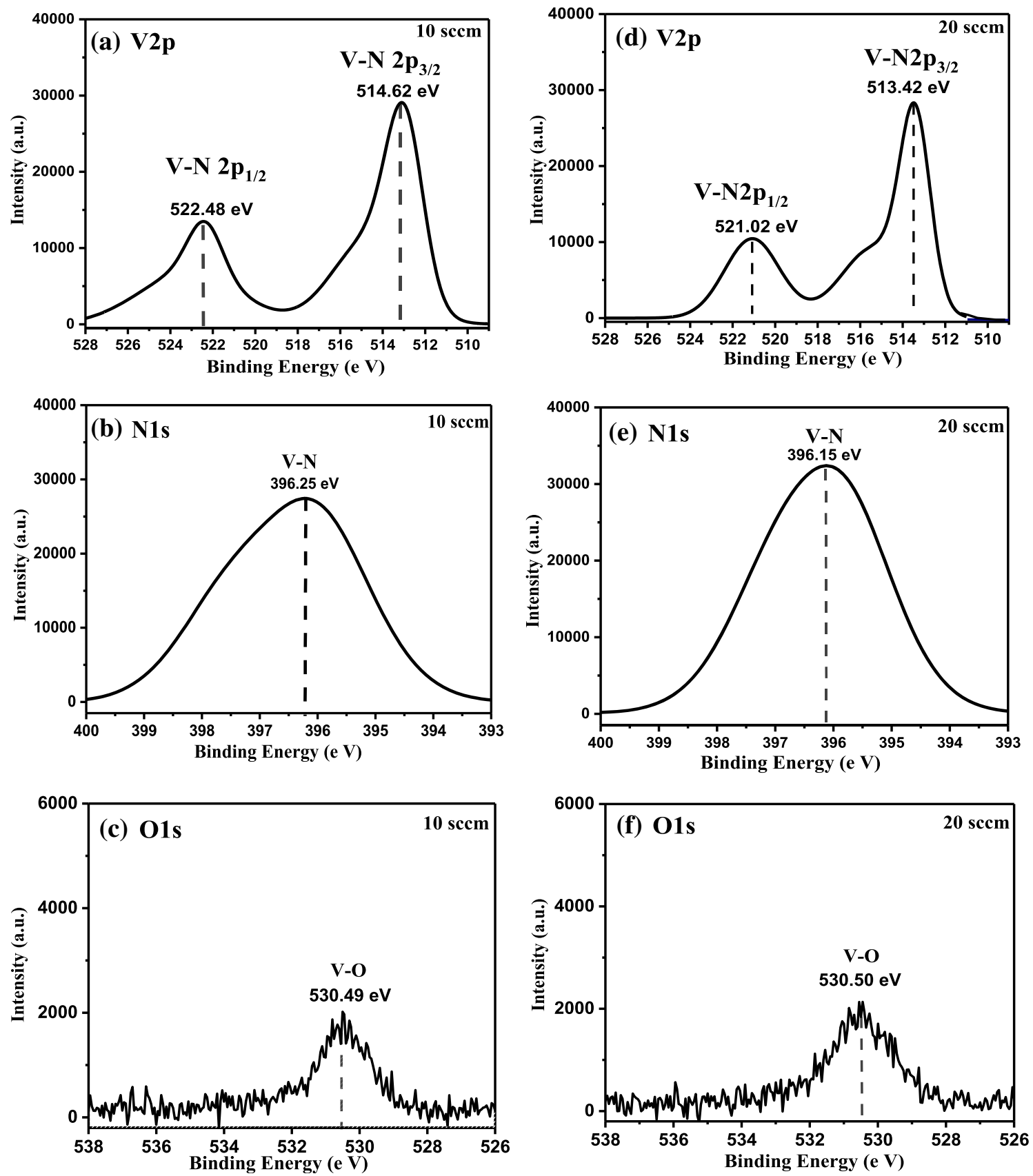

Figure $1 \mathrm{~V} 2 \mathrm{p}, \mathrm{N} 1 \mathrm{~s}$ and O1s XPS spectra of VN films deposited at 10 and $20 \mathrm{sccm}$ of $\mathrm{N}_{2}$.

2 peak includes two components, corresponding to nitride $\mathrm{VN}(513.32 \mathrm{eV})$ and oxide $\mathrm{V}_{2} \mathrm{O}_{5}(516.03 \mathrm{eV})$, respectively (Fig. 1d) [32]. Peak corresponding to $\mathrm{V}_{2} \mathrm{~N}$ phase disappeared at $20 \mathrm{sccm}$. The strong N1s peak is centered at $396.15 \mathrm{eV}$ corresponding to V-N and $\mathrm{V}-\mathrm{O}-\mathrm{N}$ binding energies (Fig. 1e) [33, 34]. This indicates that the $\mathrm{V}-\mathrm{N}$ bond is strongly formed in the $\mathrm{VN}$ thin films after the incorporation of nitrogen atoms and confirms transformation of $\mathrm{V}_{2} \mathrm{~N}$ into $\mathrm{VN}$ and coexistence of vanadium nitride (VN) and oxide phases in films deposited at $20 \mathrm{sccm}$ of $\mathrm{N}_{2}$ as shown later in XRD analysis. N1s peak has a higher intensity for the film deposited at $20 \mathrm{sccm}$ of $\mathrm{N}_{2}$ than that obtained at $10 \mathrm{sccm}$. This difference means, probably, that nitrogen is rather linked to vanadium during the film deposition. Generally, the V-O binding energy observed in the XPS spectra is due to the moderate vacuum and residual oxygen in deposition chamber. 
Therefore, the binding energy of O1s core level, taken at $530.50 \mathrm{eV}$ is corresponding toV-O (Fig. 1f) [33].

Figure 2a shows the XRD patterns of $\mathrm{VN}$ thin films deposited at different $\mathrm{N}_{2}$ flow rates of $5,10,15,20$ and $25 \mathrm{sccm}$. At $5 \mathrm{sccm}$, a mixture of fcc-VN and hcp$\mathrm{V}_{2} \mathrm{~N}$ phases was obtained. The VN peaks at $36.95^{\circ}$ and $42.08^{\circ}$ correspond to (111) and (200) planes, respectively (JCPDS file 073-0528). The other diffraction peaks of $\mathrm{V}_{2} \mathrm{~N}(111)$ and (200) at $39.91^{\circ}$ and $41.07^{\circ}$, respectively (JCPDS file 032-1413), were also detected. With an increasing nitrogen flow to $10 \mathrm{sccm}$, in addition to $\mathrm{V}_{2} \mathrm{~N}$ peaks, was noticed the fcc- $\mathrm{VN}$ phase at $43.48^{\circ}$ showing a (200) predominate plane with other peaks at $37.48^{\circ}, 62.72^{\circ}$ and $74.95^{\circ}$ corresponding to (111), (220) and (311) planes, respectively. At the same time, $h c p-V_{2} \mathrm{~N}$ phase disappeared which is in an agreement with XPS observations. The changes in the intensity were qualitatively estimated in terms of texture coefficients $\left(\mathrm{T}_{\mathrm{C}}\right)$ calculated from the XRD peaks by using Eq. (1). Figure $2 b$ shows the (111) (200) and (220) texture coefficients of VN thin films as a function of $\mathrm{N}_{2}$ flow rate. At $5 \mathrm{sccm}$ of $\mathrm{N}_{2}$, the texture coefficient of (111) orientation was 0.43 which corresponds to a random orientation of fcc-VN indicated in the JCPDS data file. With an increase of $\mathrm{N}_{2}$ flow rate up to $10 \mathrm{sccm}, \mathrm{VN}$ film with (200) dominate orientation exhibited a higher texture coefficient in comparison to the (111) orientation. Further rising in $\mathrm{N}_{2}$ flow to 15 and $20 \mathrm{sccm}$ led to VN films with lower (200) texture coefficient and higher (111) orientation texture coefficient, respectively. The significant increase in the (111) intensity as compared to (200) plane intensity can be attributed to the competition between the surface energy and the strain energy

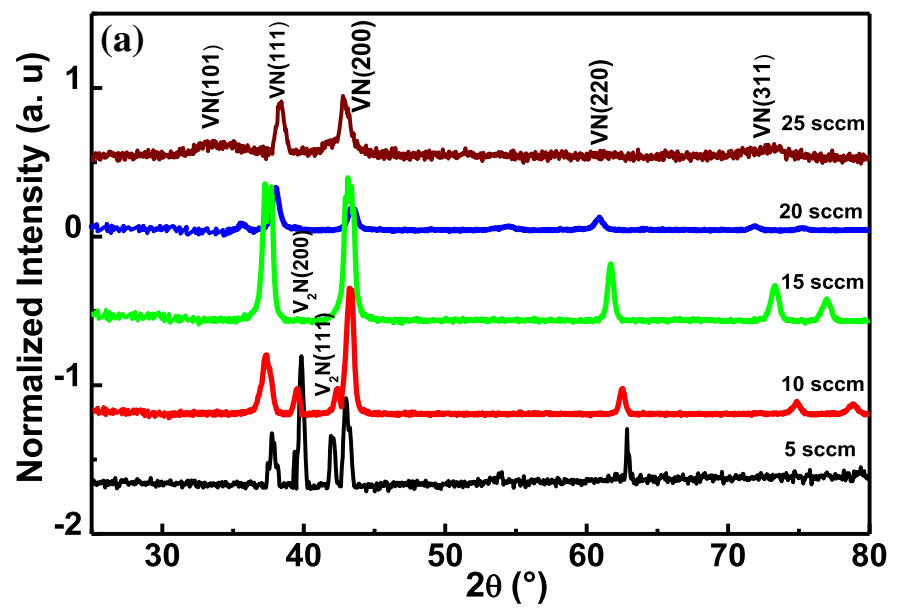

with decreasing film thickness. A high intensity of (200) plane is observed with $T_{C}$ of 0.99 and a ratio of $78 \%$ and its $2 \theta$ value is well correlated to the (JCPDS file 073-0528) for the VN thin films. The high intensity of (200) plane of VN thin films is due to the low lattice strain $(\varepsilon=-0.00197)$ [28]. The XRD spectra of $\mathrm{VN}$ films produced under further increase in $\mathrm{N}_{2}$ flow rate (15 and $20 \mathrm{sccm}$ ) reveal higher peak intensity of (111) plane with a maximum value of $\mathrm{T}_{\mathrm{C}}$ (2.2) and ratio of $78 \%$ and lower peak intensity of (200) plane $\left(\mathrm{T}_{\mathrm{C}}=1.4\right.$, ratio of $\left.25 \%\right)$ with a significant shift of $2 \theta$ angles was observed of the (220) plane $\left(T_{C}=1.1\right)$, which despaired at higher nitrogen flow rate (Fig. 2b). According to Eq. (2), we know that the (111) and (002) planes were the preferential crystallite orientation for the thin $\mathrm{VN}$ films. The $\mathrm{T}_{\mathrm{C}}(\mathrm{h} \mathrm{k}$ l) represents the texture of a particular plane, whose deviation from unity implies the preferred growth [28]. The highest $T_{C}$ was in the (111) plane and a maximum ratio of $75 \%$ for thin VN film at $20 \mathrm{sccm}$ [21]. The highest $T_{C}$ in the (111) plane is the result of an increasing lattice strain by the insertion of more nitrogen into the vanadium [28]. Huang et al. reported the same tendency of texture transition between (200) and (111) of VN films with increasing nitrogen partial pressure, which is predicted by the competitive growth theory [20].

As listed in Table 1, the lattice strain in the $\mathrm{VN}$ thin films, deposited under different $\mathrm{N}_{2}$ flow rates, is in the range from -0.00442 to 0.00052 . This has a significant effect on the increase in the (111) plane intensity due to the grown stress, which is associated with the film thickness. The plane intensity evolution may also be related to the stoichiometry and chemical

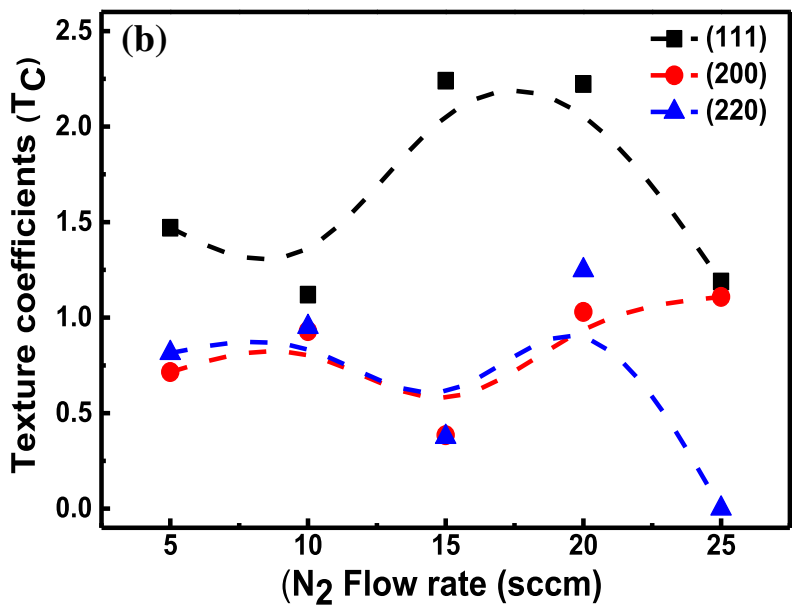

Figure 2 a XRD spectra, $\mathbf{b}$ Texture coefficients of $\mathrm{VN}$ films as a function of $\mathrm{N}_{2}$ flow rate. 
composition of the VN film. For the under-stoichiometric $\mathrm{VN}$ thin film $(\mathrm{N} / \mathrm{V}<1)$, there are fewer $\mathrm{V}-\mathrm{N}$ bonds as compared to V-V bonds and hence (200) orientation. In the case of stoichiometric composition of $\mathrm{VN}$ thin film $(\mathrm{N} / \mathrm{V} \approx 1)$, the number of $\mathrm{V}-\mathrm{N}$ bonds increased favoring the (111) plane [35].

As shown in Table 1, the increasing of lattice parameter of $\mathrm{VN}$ thin film from 0.41221 to $0.41416 \mathrm{~nm}$ with increasing $\mathrm{N}_{2}$ flow rate from 5 to 25 $\mathrm{sccm}$ can be clearly noticed. The average lattice parameter of the stoichiometric VN thin film (deposited at $20 \mathrm{sccm}$ of $\mathrm{N}_{2}$ ) was equal to $0.41396 \mathrm{~nm}$, which is in a good agreement with the theoretical value $(0.41391 \mathrm{~nm})$ indicated in the JCPDS file 073-0528. Thus, the results reveal an increase in lattice parameter of fcc-VN phase, which is in an agreement with the literature [36, 37]. According to our previous work [21], the rising of lattice parameter may be attributed to the increase of $\mathrm{N} / \mathrm{V}$ ratio in $\mathrm{VN}$ thin films.

\section{Surface topography and film morphology}

The surface and cross-sectional morphology of $\mathrm{VN}$ thin films deposited at 10, 15 and $20 \mathrm{sccm}$ of $\mathrm{N}_{2}$ flow rates are shown in Fig. 3. As the flow rate is increased from 5 to $10 \mathrm{sccm}$ (Fig. 3a, b), the film surface morphology shows a faceted and a relatively rough surface $\left(R_{a}=25-37 \mathrm{~nm}\right)$. The cross-sectional image shows a columnar structure (with a film thickness of $1240 \mathrm{~nm}$ ) as shown in Fig. 3a, b. Figure 3c shows that increasing nitrogen flow rate to $15 \mathrm{sccm}$ results in are duction in the grain size separated by voids. Reduction in both crystallite size and surface roughness is attributed to the dense structure and the smooth surface features. At $20 \mathrm{sccm}$ of $\mathrm{N}_{2}$, a completely different evolution was found where a columnar structure consisted of non-separable grains with apparently globular-like features (Fig. 3d). Furthermore, the structure was denser with a smoother surface $\left(\mathrm{R}_{\mathrm{a}}=6 \mathrm{~nm}\right)$ as a result of the fcc-VN phase stability $(\mathrm{N} / \mathrm{V} \approx 1)$. According to Zhou et al. [38], nitrogen plays an important role in the film smoothening due to the presence of more nuclei. By increasing nitrogen flow rate, the thickness of the $\mathrm{VN}$ thin film decreased with no significant difference in the film growth morphology. This is due to the increasing density of gas molecules with increasing $\mathrm{N}_{2}$ flow rate that leads to more collisions and consequently a reduction in the film thickness [39].
Furthermore, the sputtering rate of nitrides is lower than that of metals and the metal nitride by the poisoning of the target at high nitrogen flow, which further decreases the sputtering yield of the targets [38]. The contamination of the vanadium target by nitrogen can also be another reason for the reduction in the film thickness [20, 38]. At higher nitrogen flow rate, the surface roughness slightly increased with an increase in grain size and a decrease in the film thickness (Fig. 3e).

\section{Mechanical properties}

\section{Residual stress measurements}

Figure 4 shows the evolution of residual stress in the films deposited at different $\mathrm{N}_{2}$ flow rates. In all VN thin films, a compressive stress state was observed. By increasing the $\mathrm{N}_{2}$ flow rate from 5 to $15 \mathrm{sccm}$, the residual stress increased about three times from -0.54 to-1.7 GPa. This can be related to the high density of the grain boundaries and defects as well as the coexistence of $\mathrm{VN}$ and $\mathrm{V}_{2} \mathrm{~N}$ phases as confirmed by XRD and XPS analyses [40, 41]. From Fig. 4, we can see that, a further increase in the $\mathrm{N}_{2}$ flow rate to 20 sccm did not lead to any changes in the stress state, which is related to the progressive appearance of more stable $\mathrm{VN}$ phase [42]. The $\mathrm{VN}$ film deposited at $25 \mathrm{sccm}$ of $\mathrm{N}_{2}$ presented lower stress where the $\mathrm{VN}$ phase was dominant. This is due to the reduction in the amount of interstitial defects by the incorporation of more nitrogen atoms in the vanadium lattice as well as the decrease of the crystalline size [41].

\section{Hardness and elastic modulus}

The hardness $(\mathrm{H})$ and Young's modulus $(\mathrm{E})$ of the VN thin films are presented in Fig. 5a. Depending on the $\mathrm{N}_{2}$ flow rate (the nitrogen content in the films), the hardness values are in the range of 11-26.2 GPa. Figure $5 c$ shows clearly the relationship between the film hardness and residual stress.

It can be noticed that increasing the $\mathrm{N}_{2}$ flow rate led to an increase the hardness of $\mathrm{VN}$ thin films. Its maximum value of $26.2 \mathrm{GPa}$ was obtained for the film deposited at $20 \mathrm{sccm}$ of $\mathrm{N}_{2}$. It has been observed earlier by Caicedo et al. [17], that the lowest hardness of $11 \mathrm{GPa}$ was obtained for $\mathrm{VN}$ films deposited without bias voltage presenting a $\mathrm{N} / \mathrm{V}$ ratio equal to 1. With further increase in bias voltage, the N/V ratio 

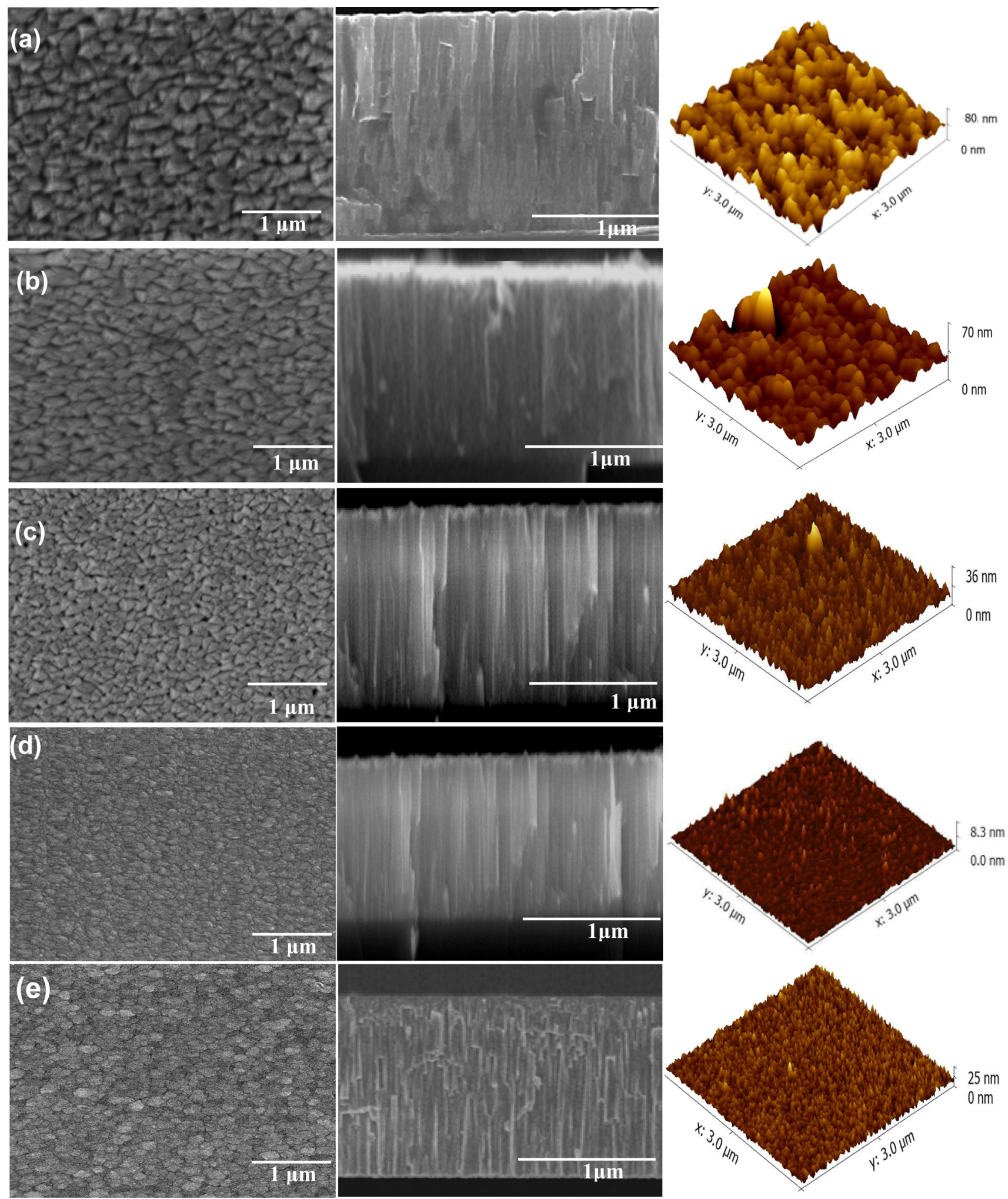

Figure 3 SEM and AFM images of the VN thin films deposited at: a $5 \mathrm{sccm}, \mathbf{b} 10 \mathrm{sccm}, \mathbf{c} 15 \mathrm{sccm}, \mathbf{d} 20 \mathrm{sccm}$ and e $25 \mathrm{sccm}$ of $\mathrm{N}_{2}$ flow rates. 


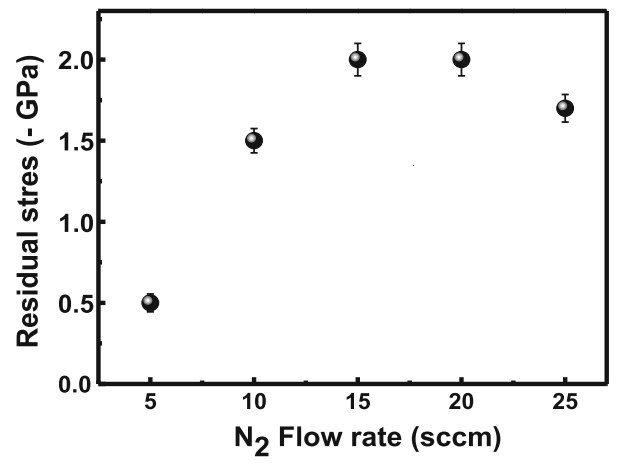

Figure 4 Evolution of residual stress in $\mathrm{VN}$ thin films as a function of $\mathrm{N}_{2}$ flow rate.

increased up to 1.14 and the hardness was enhanced to reach a maximum value of $20 \mathrm{GPa}$. It is evident that at $25 \mathrm{sccm}$ of $\mathrm{N}_{2}$, when the $\mathrm{N} / \mathrm{V}$ ratio was 1.17 , the film hardness slightly decreased to $25 \mathrm{GPa}$, which is lower than the value (29 GPa) obtained in our previous study [21]. According to Korneev et al. [43], an increase in film hardness is attributed to the solid
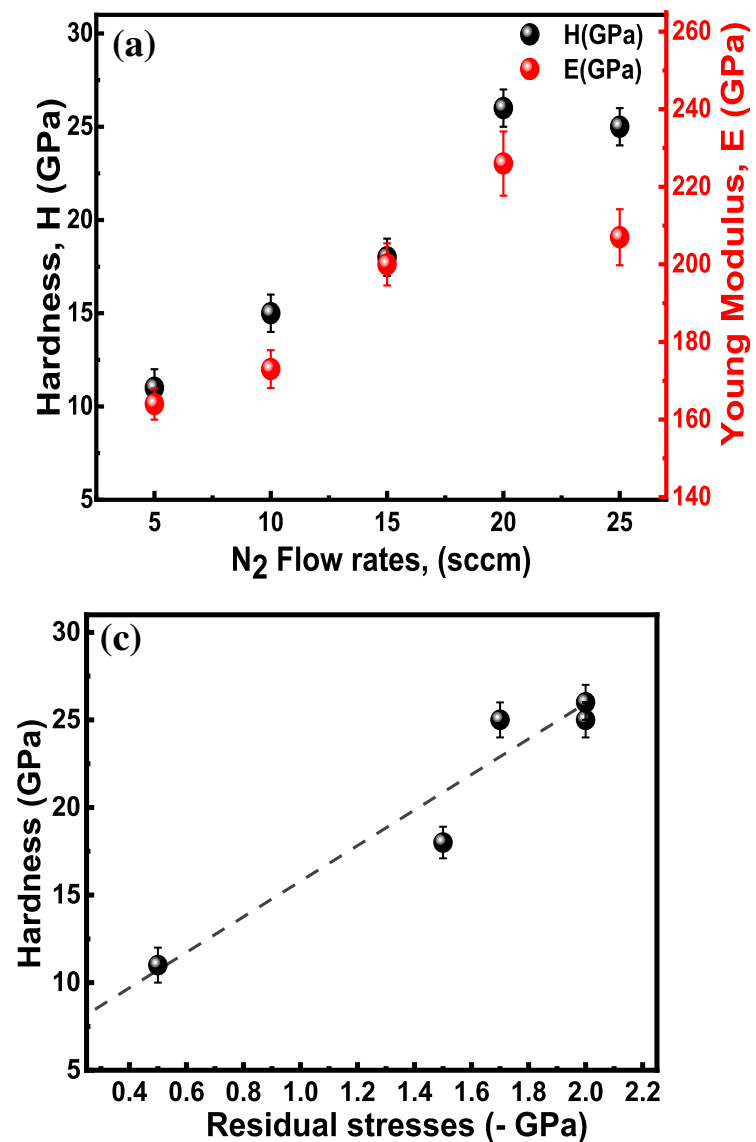

solution strengthening by the formation of stoichiometric structure, high compressive stress and lattice distortions related to structural defects. Besides, the reduction of hardness may be due to the formation of vanadium oxide phase [21].

Influence of porosity on the measured Young's modulus of the VN coatings was observed. Results suggest that the Young's modulus of VN thin films is strongly dependent on the amount of porosity and type of microstructure. The Young's modulus of the dense film at higher nitrogen flow rate is more than that of the film with a columnar structure. The decrease in Young's modulus can be explained by the fact that the columnar structures become more porous, with feather-like structures and an increased number of intra-columnar pores in the columns, which is consistent with several works in the literature of the bulk materials [44, 45]. Moreover, the hardness of the VN films a dense structure is more than that of the film with columnar structures in the surface regions of the coatings. This distinct
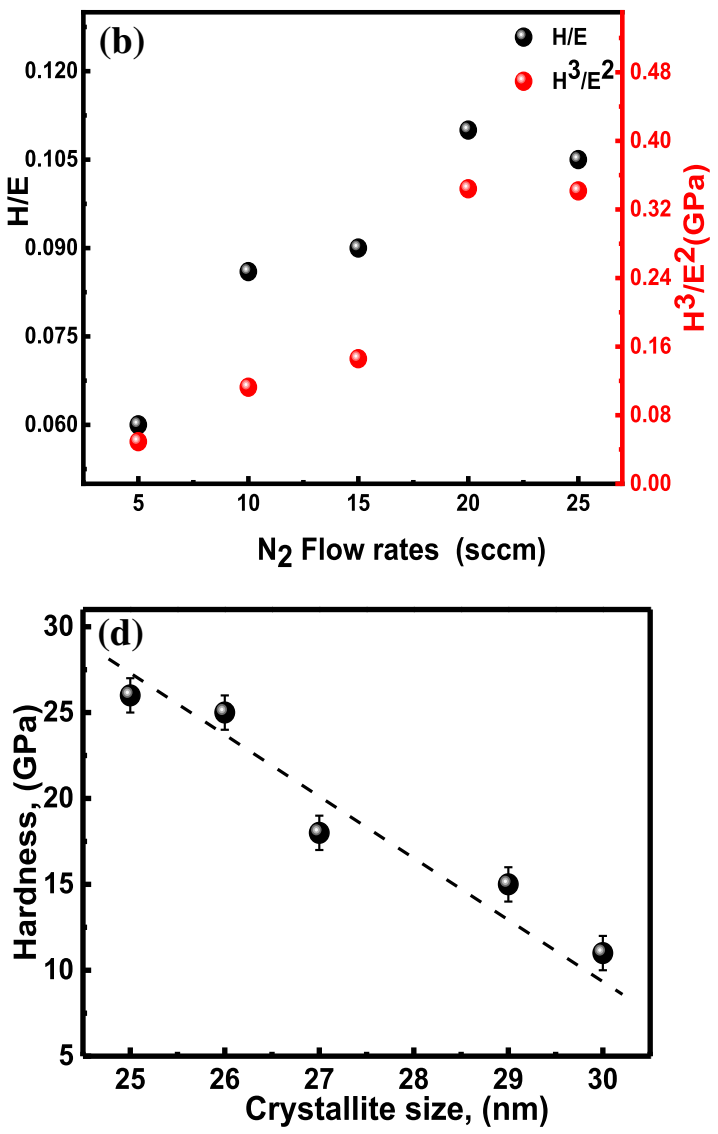

Figure 5 a Hardness and Young's modulus, and $\mathbf{b}\left(\mathrm{H} / \mathrm{E}, \mathrm{H}^{3} / \mathrm{E}^{2}\right)$ ratios as a function of $\mathrm{N}_{2}$ flow rate, Hardness as a function of: $\mathbf{c}$ residual stress, and $\mathbf{d}$ crystallite size of $\mathrm{VN}$ thin films. 
difference in behavior of the hardness and Young's modulus with film density in the VN thin films shows that the columnar structure produces anisotropic mechanical properties that are very different to those of their dense compact.

According to the literature, $(\mathrm{H} / \mathrm{E})$ and $\left(\mathrm{H}^{3} / \mathrm{E}^{2}\right)$ are very important parameters [21, 47]. The $\mathrm{H} / \mathrm{E}$ ratio can be used as an indicator for the elastic behavior of the surface in contact with external forces and the plasticity index $\left(\mathrm{H}^{3} / \mathrm{E}^{2}\right)$ is reported to be a close measure of toughness, which allows the determination of elastic and plastic deformation resistance and rank the coatings accordingly [45]. The values of $(\mathrm{H} /$ E) and $\left(\mathrm{H}^{3} / \mathrm{E}^{2}\right)$ calculated from hardness and Young modulus are shown in Fig. $5 \mathrm{~b}$. By increasing the $\mathrm{N}_{2}$ flow rate, the highest values of $\mathrm{H} / \mathrm{E}(0.124)$ and $\mathrm{H}^{3}$ / $\mathrm{E}^{2}(0.474 \mathrm{GPa})$ ratios were obtained in the film sputtered at $20 \mathrm{sccm}$ (Fig. 5b), which indicate a greater toughness and resistance to abrasion.

The increase in the elasto-plastic index with higher hardness can be explained by the high dense structure and the high (111) textured plane due to the incorporation of nitrogen in the vanadium lattice and the formation of the $\mathrm{VN}$ phase, which is denser in comparison to the $\mathrm{V}_{2} \mathrm{~N}[21,46]$. Moreover, the best mechanical is due to the high content of $\mathrm{V}-\mathrm{N}$ binging energy and solid solution hardening from the nitrogen atoms in the VN films as compared to the pure vanadium, which is consistent with several works in the literature [46, 47].

Figure $5 \mathrm{~d}$ shows the variation of hardness of the VN thin films as a function of the crystallite size of VN phase. This figure reveals an inverse relationship between the crystallite size and hardness, suggesting that a higher crystallite size corresponds to lower hardness. Hence, it can be inferred that increasing the nitrogen content helps in the grain refining of the VN film by the formation of more interfaces which block the dislocations movement, and thus strengthening the films, as described by Hall-Petch relationship [41, 49]. It has been shown by Huang et al. [20] that at $\mathrm{N} / \mathrm{V}$ ratio $=1$, the crystallite size was about $15 \mathrm{~nm}$ and the texture coefficients were 0.35 (111) and 0.65 (200) corresponding to 30 GPa super hard VN film. In the present study, the minimum crystallite size of $25 \mathrm{~nm}$ was obtained in film containing 49.5 at.\% of nitrogen (N/V ratio close to 1), deposited at $20 \mathrm{sccm}$ of $\mathrm{N}_{2}$, with a maximum average hardness of 26.2 $\mathrm{GPa}$.
The Young's modulus of VN thin films was found to be between 164 and $226 \mathrm{GPa}$. This is considerably lower than the value (370 GPa) obtained by Huang et al. for $\mathrm{VN}$ thin film deposited by an unbalanced magnetron sputtering [20]. This significant difference may be attributed to the influence of high compressive stress, grain refinement and lower surface roughness, playing an important role in the nanoindentation measurements $[2,21]$. The low Young's modulus values can also be explained by the increase of the fcc-VN phase fraction and the high residual porosity in the film because of the columnar structure [50]. According to Leyland et al. [30], the combination of high hardness and low Young's modulus enhances the film adhesion to substrate and provides better wear resistance.

\section{Friction behavior and wear resistance}

Figure 6a illustrates the friction coefficients and wear rates for all VN thin films deposited on XC100 steel substrates tested against $100 \mathrm{Cr} 6$ balls at room temperature under dry conditions. In the initial stage of sliding, a low value of friction coefficient $(\mathrm{CoF})$ is observed, which then rises rapidly to a constant level after approximately $25 \mathrm{~m}$ of sliding distance, representing a transition pattern of friction for rough surfaces. According to our previous study [21], the low CoF value in the initial stages of the sliding test is due to the high surface roughness resulting in a small contact area between the film surface and the ball.

The average friction coefficient of the $\mathrm{VN}$ thin film deposited at $5 \mathrm{sccm}$ of $\mathrm{N}_{2}$ was 0.61 . This high value can be related to the hcp $-\mathrm{V}_{2} \mathrm{~N}$ phase [21]. The VN film containing 49.5 at.\% of nitrogen, deposited at $20 \mathrm{sccm}$ of $\mathrm{N}_{2}$, presented the lowest friction coefficient of 0.37 . Zhang et al. [50] reported a similar mechanism obtained during wear testing of sputtered TiN coatings used for synchronizer ring. Change in friction coefficient might be related to the formation of oxide phase $\left(\mathrm{V}_{2} \mathrm{O}_{5}\right)$ on the surface of $\mathrm{VN}$ coating deposited at $20 \mathrm{sccm}$. Presence of this phase on the surface was confirmed by XPS analysis. $\mathrm{V}_{2} \mathrm{O}_{5}$ phase along with other $\mathrm{V}-\mathrm{O}$ phases $\left(\mathrm{V}_{\mathrm{n}} \mathrm{O}_{2 \mathrm{n}-1}\right.$ and $\left.\mathrm{V}_{\mathrm{n}} \mathrm{O}_{3 \mathrm{n}-1}\right)$ exhibit remarkable properties including oxidation stability, low adhesion as well as self-lubrication due to availability of easy sharable crystallographic defect planes [32].

The calculated wear rates of the VN thin films are illustrated in Fig. 6b. The wear rates of all VN thin 

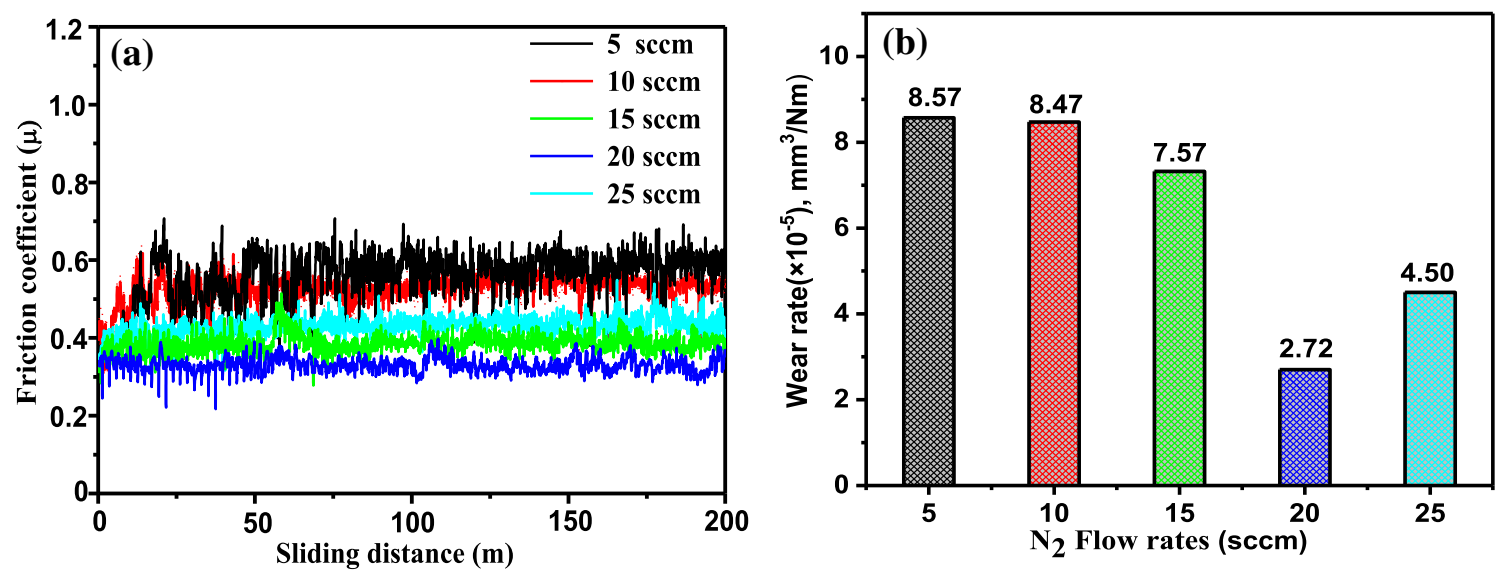

Figure 6 a Friction coefficients and $\mathbf{b}$ Wear rates of the $\mathrm{VN}$ thin films deposited at different $\mathrm{N}_{2}$ flow rates.

films are lower than those of the $\mathrm{VN}$ films deposited by cathodic arc ion plating method due to the lubrication effect of vanadium oxide formed in VN films [51]. The wear rate of the VN films decreased with increasing nitrogen flow rate, signifying an enhancement in their wear resistance. The lowest wear rate of $2.72 \times 10^{-5} \mathrm{~mm}^{3} / \mathrm{N} \bullet \mathrm{m}$ was obtained for the $\mathrm{VN}$ film deposited at $20 \mathrm{sccm}$ of $\mathrm{N}_{2}$. In order to describe the wear characteristics more clearly, SEM and two-dimensional profilometer images of wear tracks were acquired (Figs. 7 and 8). For the VN film deposited at $10 \mathrm{sccm}$ of $\mathrm{N}_{2}$, the wear track was seriously worn and a delamination fracture of the $\mathrm{VN}$ thin film from the XC100 substrate was observed with a wear track depth of about $0.80 \mu \mathrm{m}$, indicating that the film has undergone severe abrasive wear. The wear debris produced during this abrasive wear could have further caused severe three-body wear at the interface resulting in increased wear (Fig. $7 \mathrm{~b}$ ). Between 5 and $10 \mathrm{sccm}$ of $\mathrm{N}_{2}$, the SEM images of the wear tracks show the presence of significant debris around the edges with a pronounced wear track depth (Figs. 7a, b, 8a, b). Thus, this may have significantly contributed to a noticeable increase in the friction coefficient value between the surfaces of the VN film and the 100Cr6 ball [52].

For the films deposited at 15 and $20 \mathrm{sccm}$ of $\mathrm{N}_{2}$, the wear track depths were about 0.75 and $0.70 \mu \mathrm{m}$, respectively, signifying the fact that increasing nitrogen content in the films enhances the film wear resistance [1]. Moreover, the wear tracks revealed a small amount of debris that indicating an improved tribological performance of the films with increasing nitrogen content in the VN thin films (Fig. 7c, d). The $\mathrm{V}-\mathrm{N}$ coatings deposited at 15 and $20 \mathrm{sccm}$ of $\mathrm{N}_{2}$ confirm increased wear resistance with lower wear rates (Fig. $8 b, c$ ), which is attributed to their dense structure, low surface roughness and high hardness value [21, 52].

EDS analysis was conducted to evaluate the elemental compositions on the wear track after the tests as shown in Fig. 9. The wear tracks on the $\mathrm{VN}$ thin films deposited at 5, 10 and $25 \mathrm{sccm}$ flow rates of $\mathrm{N}_{2}$ showed the presence of iron peak, corresponding to the XC100 steel substrate with a small amount V and $\mathrm{N}$. The high iron concentrations in worm track of the $\mathrm{VN}$ thin films indicate low films/substrate adhesion due to the low film thicknesses which affect negatively on the wear rate and friction coefficient values. However, the high $\mathrm{V}$ and $\mathrm{N}$ were noticed in case of the $\mathrm{VN}$ films deposited at $20 \mathrm{sccm}$ of $\mathrm{N}_{2}$ flow rate, suggesting a stronger adhesion between the film and the substrate due to the dense structure and good mechanical properties of the film.

Improving the mechanical properties in terms of enhanced hardness, Young's modulus and H/E and $\mathrm{H}^{3} / \mathrm{E}^{2}$ ratios of the VN films, results in increased resistance to brittle cracking, which is directly related to the tribological performance of the films. Hence, the worn surface of the films deposited at $5 \mathrm{sccm}$ of $\mathrm{N}_{2}$, with lower $\mathrm{H} / \mathrm{E}$ and $\mathrm{H}^{3} / \mathrm{E}^{2}$ values, shows poor tribological performance with brittle features (Fig. 8c. The worn surface of $\mathrm{VN}$ thin film at $20 \mathrm{sccm}$ of $\mathrm{N}_{2}$ with higher $\mathrm{H} / \mathrm{E}$ and $\mathrm{H}^{3} / \mathrm{E}^{2}$ shows the lowest wear rate (Fig. 6c. Moreover, it is also to be noted that many other variables may influence wear behavior such as crystal structure, grain refinement and reactivity between the coating and sliding material. The Hall-Petch strengthening with decrease in grain size leads to enhanced yield strength of the material and 

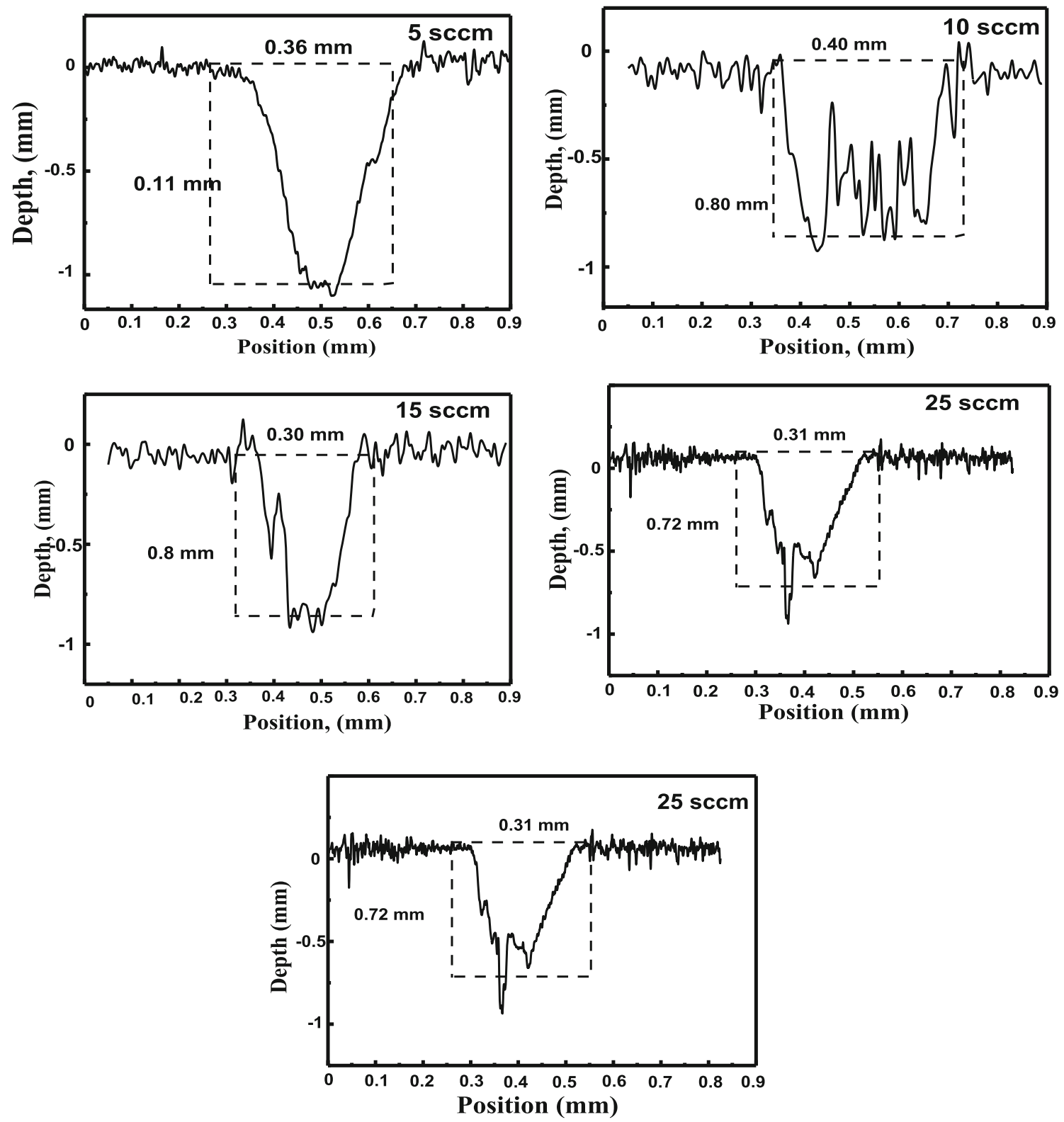

Figure 7 Wear depth tracks of $\mathrm{VN}$ thin films deposited at different $\mathrm{N}_{2}$. Flow rates.

increases the hardness. It also blocks the propagation of cracks and dislocations and avoids the continuity of pores or pinholes in the deposited films [21]. Few studies have recently reported on the beneficial impact of nitrogen flow rate on crack deflections in TiN coatings [46].

\section{Conclusions}

In the present work, $\mathrm{VN}$ thin films were deposited on XC100 steel substrates and Si wafers by R.F. magnetron sputtering technique. The relationship between residual stress, lattice, grain size, phases and tribo-mechanical properties was illustrated. With increasing nitrogen content, coating composition changed from a mixture of $\mathrm{V}_{2} \mathrm{~N}$ and $\mathrm{VN}$ phases to pure VN. The high intensity of (200) plane was obtained in films containing low nitrogen concentration, while the high intensity of (111) plane was 

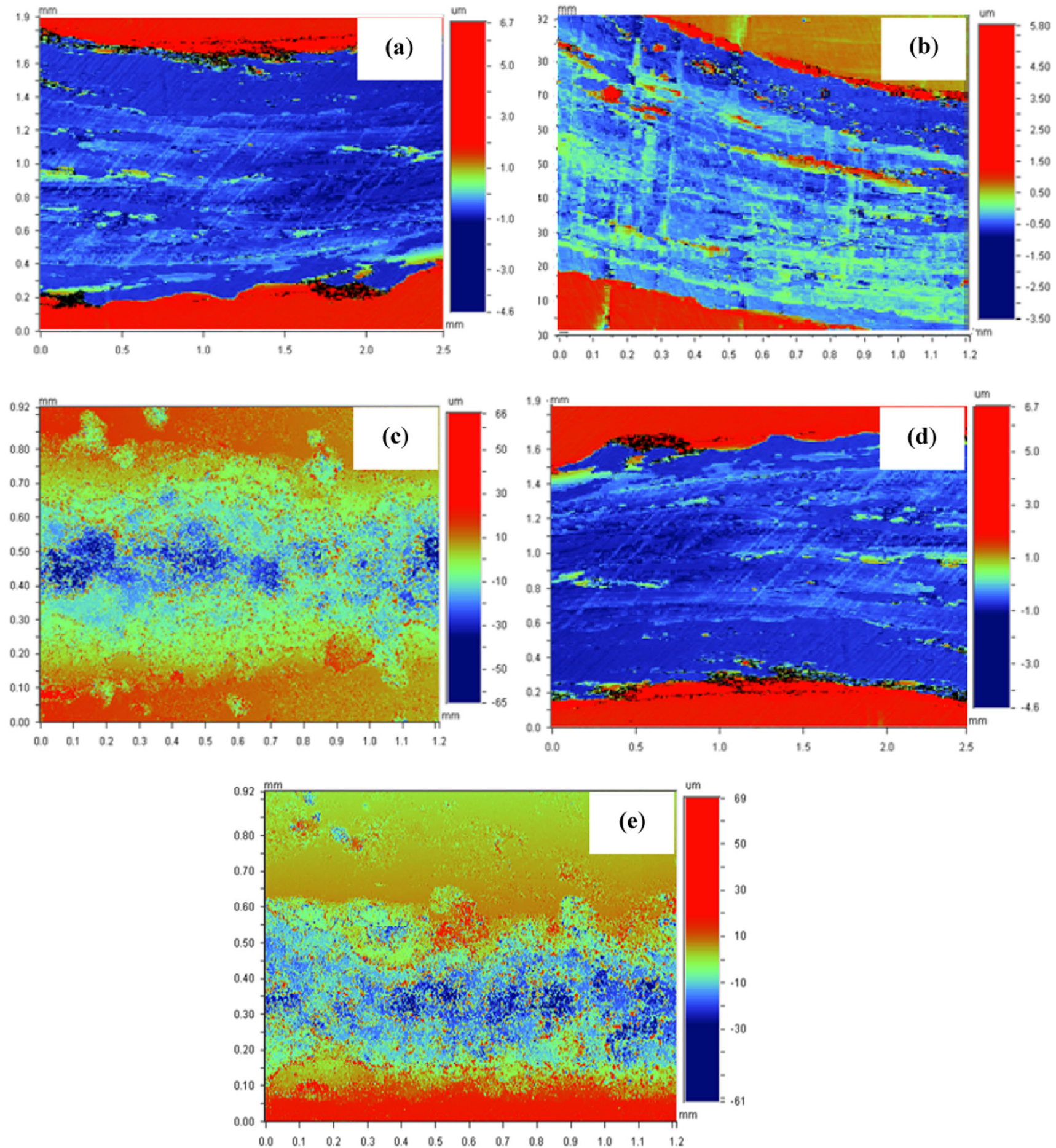

Figure 8 a Two-dimensional morphologies of wear tracks of VN thin films deposited under: a $5 \mathrm{sccm}, \mathbf{b} 10 \mathrm{sccm}, \mathbf{c} 15 \mathrm{sccm}, \mathbf{d} 20 \mathrm{sccm}$ and e $25 \mathrm{sccm}$ of $\mathrm{N}_{2}$.

remarkable in VN films deposited at higher nitrogen flow rate, which attributed to increase in the residual stress, and the film stoichiometry.

All films showed columnar structure. The addition of nitrogen clearly resulted in the formation of smooth films with fine grains. The average roughness of VN film was reduced from 25 to $6 \mathrm{~nm}$ with increasing $\mathrm{N}_{2}$ flow rate. Mechanical and tribological properties of $\mathrm{VN}$ thin films were considerably improved, and VN film deposited at $20 \mathrm{sccm}$ of $\mathrm{N}_{2}$ 

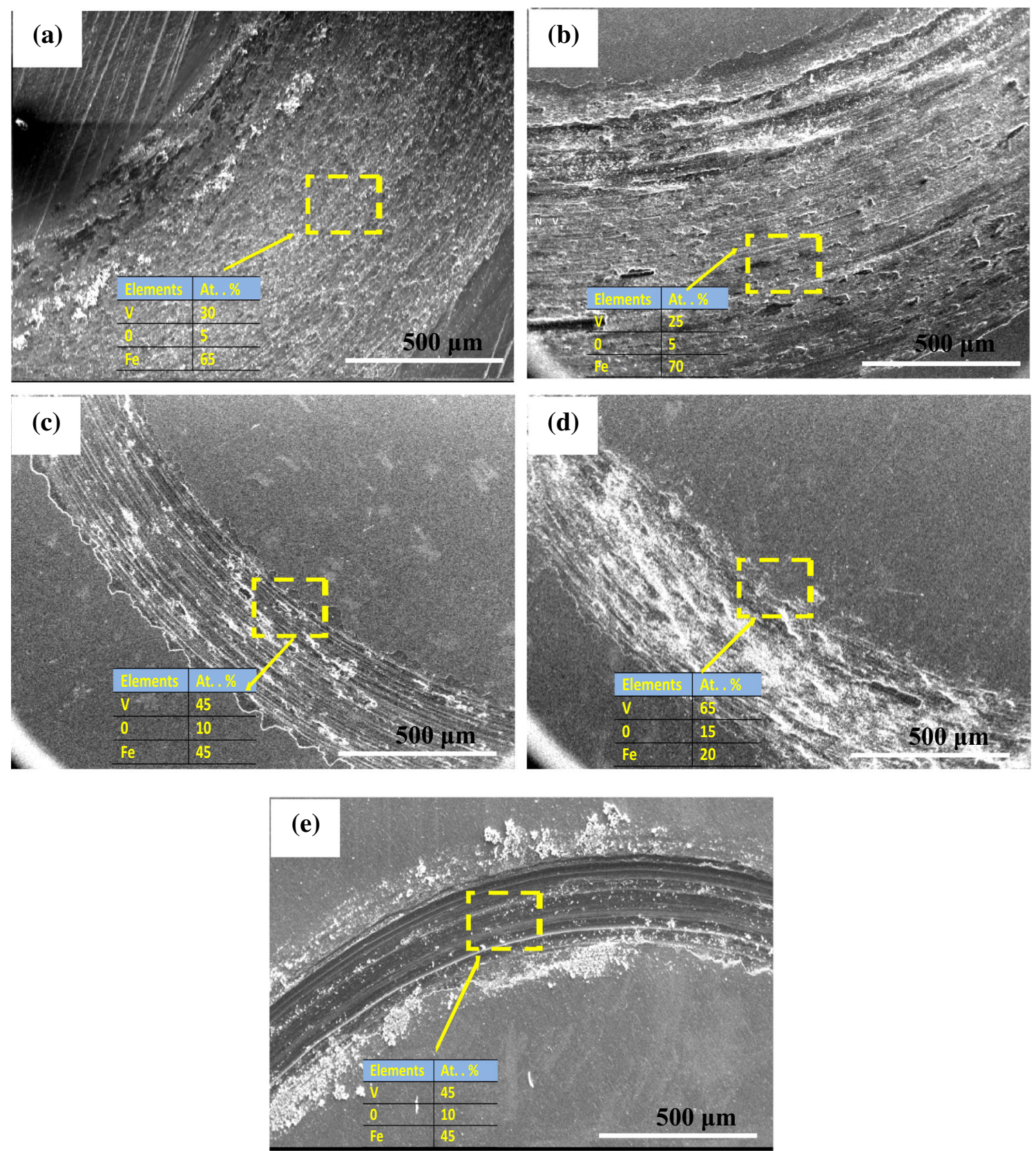

Figure 9 SEM morphologies of wear track of VN thin films deposited under: a $5 \mathrm{sccm}$, b $10 \mathrm{sccm}$, c $15 \mathrm{sccm}, \mathbf{d} 20 \mathrm{sccm}$ and e $25 \mathrm{sccm}$ of $\mathrm{N}_{2}$.

had optimized properties. This film presented the highest hardness, lowest wear rate and a good friction coefficient of 0.37 .

\section{Acknowledgements}

The authors gratefully acknowledge the LaBoMaP of Arts et Metiers Institute of Technology in Cluny for their help in the deposition and characterization of coatings.

\section{Funding}

Open Access funding enabled and organized by Projekt DEAL. 
Open Access This article is licensed under a Creative Commons Attribution 4.0 International License, which permits use, sharing, adaptation, distribution and reproduction in any medium or format, as long as you give appropriate credit to the original author(s) and the source, provide a link to the Creative Commons licence, and indicate if changes were made. The images or other third party material in this article are included in the article's Creative Commons licence, unless indicated otherwise in a credit line to the material. If material is not included in the article's Creative Commons licence and your intended use is not permitted by statutory regulation or exceeds the permitted use, you will need to obtain permission directly from the copyright holder. To view a copy of this licence, visit http://creativecommons.org/licen ses/by $/ 4.0 /$.

\section{References}

[1] Ermolenko M-V, Zavadski S-M, Golosov D-A, Melnikov S-N, Zamburg E-G (2016) Tribologicalbehavior of TiN films deposited by reactive magnetron sputtering under low pressure. J Friction Wear 37(3):289-292

[2] Aissani L, Nouveau C, Walock MJ, Djebaili H, Djelloul A (2015) Influence of vanadium on structure, mechanical and tribological properties of $\mathrm{CrN}$ coatings. Surf Eng 31(10):779-788

[3] Krishna M-G, Bhattacharya AK (1999) Optical and electrical properties of vanadium nitride thin films. Int J Mod Phys B 13(7):833-839

[4] C.-Y. Pu, D.-W. Zhou, D.-X. Bao, C. Lu, X.-L. Jin, T.-C. Su, F.-W. Zhang, Elastic and thermodynamic properties of vanadium nitride under pressure and the effect of metallic bonding on its hardness, Chinese Physics B 23(2) (2014) (026201) 1-6

[5] Huber Š, Jankovský O, Sedmidubský D, Luxa J, Klímová K, Hejtmánek J, Sofer Z (2016) Synthesis, structure, thermal, transport and magnetic properties of $\mathrm{VN}$ ceramics. Ceram Int 42(16):18779-18784

[6] Kwon H, Choi S, Thompson L-T (1999) Vanadium nitride catalysts: synthesis and evaluation forn-butane dehydrogenation. J Catal 184(1):236-246

[7] Wiklund U, Casas B, Stavlid N (2006) Evaporated vanadium nitride as a friction material in dry sliding against stainless steel. Wear 261(1):2-8

[8] Chun S-Y (2017) Properties of VN coatings deposited by ICP assisted sputtering: effect of ICP power. J Korean Ceram Soc 54(1):38-42
[9] Ouldhamadouche N, Achour A, Lucio-Porto R, Islam M, Solaymani S, Arman A, Ahmadpourian A, Achour H, Brizoual L, Djouadi MA, Brousse T (2018) Electrodes based on nano-tree-like vanadium nitride and carbon nanotubes for micro-supercapacitors. J Mater Sci Technol 34:976-982

[10] Zhang J, Li X, Dong X, Dong H, Oganov A-R (2020) Theoretical study of the pressure-induced structure, phase transition, mechanical and electronic properties in the V-N system. cond-mat.mtrl-sci., preprint, arXiv:2003.00036

[11] Hofer E, Warbichler P, Scott A, Brydson R, Galesic I, Kolbesen B, Microsc J (2001) Electron energy loss near edge structure on the nitrogen K-edge in vanadium nitrides. J Microscopy 204:166-171

[12] Wiemer C, SanjineÂs R, LeÂvy F (1996) Deposition and characterization of refractory ternary phases: the transition metal nitride $\mathrm{Ti}_{1-x} \mathrm{Mo}_{x} \mathrm{~N}_{y}$. Surf Coat Technol 86:372-376

[13] Aperador W, Duque J, Delgado E (2016) Mechanical, Microstructural and tribo-electrochemistry characterization in aqueous media of coatings vanadium/vanadium nitride used as functional coating for implants. Int $\mathrm{J}$ Electrochem Sci 11:4688-4700

[14] Navarro-Devia J-H, Amaya C, Caicedo J-C, Aperador W (2017) Performance evaluation of HSS cutting tool coated with hafnium and vanadium nitride multilayers, by temperature measurement and surface inspection, on machining AISI 1020 steel. Surf Coat Technol 332:484-493

[15] Chu X, Barnett S-A, Wong M-S, Sproul W-D (1996) Reactive magnetron sputter deposition of polycrystalline vanadium nitride films. J Vac Sci Technol, A 14(6):3124-3129

[16] Suszko T, Gulbiński W, Urbanowicz A (2011) Preferentially oriented vanadium nitride films deposited by magnetron sputtering. Mater Lett 65(14):2146-2148

[17] Caicedo J-C, Zambrano G, Aperador W, Alarcon L-E, Camps E (2011) Mechanical and electrochemical characterization of vanadium nitride (VN) thin films. Appl Surf Sci 258(1):312-320

[18] Qiu Y, Zhang S, Li B, Lee J-W, Zhao D (2012) Influence of nitrogen partial pressure and substrate bias on the mechanical properties of VN coatings. Procedia Engineering $36: 217-225$

[19] Toth H-L (2014) Transition metal carbides and nitrides. Elsevier Science

[20] Huang J-H, Lin C-H, Yu G-P (2019) Texture evolution of vanadium nitride thin films. Thin Solid Films 688(137415):1-10

[21] Aissani L, Alhussein A, Nouveau C, Ghelani L, Zaabat M (2019) Influence of film thickness and $\mathrm{Ar}-\mathrm{N}_{2}$ plasma gas on the structure and performance of sputtered vanadium nitride coatings. Surf Coat Technol 378(25):124948 
[22] Huang J-H, Lau K-W, Yu G-P (2005) Effect of nitrogen flow rate on structure and properties of nanocrystallineTiN thin films produced by unbalanced magnetron sputtering. Surf Coat Technol 191:17-24

[23] Warren B-E (1969) X-ray Diffraction, Addison Wesley Publishing Co., London p. 381

[24] Greczynski G, Hultman L (2020) X-ray photoelectron spectroscopy: towards reliable binding energy referencing. Progress Mater Sci 107:100591

[25] Zheng X-H, Walmsley D-G (2015) Discrepancy between theory and measurement of superconducting vanadium. Physica C 515:41-48

[26] Lin Y-W, Lu C-W, Yu G-P, Huang J-H (2016) Structure and properties of nanocrystalline (TiZr) $x \mathrm{~N} 1-x$ thin films deposited by DC unbalanced magnetron sputtering. J Nanomater 2016:2982184

[27] Aissani L, Fellah M, Radjehi L, Nouveau C, Montagne A, Alhussein A (2019) Effect of annealing treatment on the microstructure, mechanical and tribological properties of chromium carbonitride coatings. Surf Coat Technol 359:403-413

[28] Pelleg J, Zevin L-Z, Lungo S, Croitoru N (1991) Reactivesputter-deposited TiN films on glass substrates. Thin Solid Films 197:117-128

[29] Liao M-J, Gotoh Y, Tsuji H, Ishikawa J (2004) Crystallographic structure and composition of vanadium nitride films deposited by direct sputtering of a compound target. J Vac Sci Technol A 22:146-150

[30] Sanjinés R, Hones P, LeÂvy F (1998) Hexagonal nitride coatings: electronic and mechanical properties of $\mathrm{V}_{2} \mathrm{~N}, \mathrm{Cr}_{2} \mathrm{~N}$ and d-MoN. Thin Solid Films 332:225-229

[31] SanjineÂs R, Hones P, LeÂvy F (1998) Hexagonal nitride coatings: electronic and mechanical properties of $\mathrm{V}_{2} \mathrm{~N}, \mathrm{Cr}_{2} \mathrm{~N}$ and d-MoN. Thin Solid Films 332:225-229

[32] Glaser A, Surnev S, Netzer FP, Fateh N, Fontalvo GA, Mitterer C (2007) Oxidation of vanadium nitride and titanium nitride coatings. Surf Sci 601:1153-1159

[33] Osonkie V, Chukwunenye PL, Cundari T, Kelbera J (2020) Plasma modification of vanadium oxynitride surfaces: characterization by in situ XPS experiments and DFT calculations. J Chem Phys 153(144709):1-8

[34] Liu H-H, Zhang H-L, Xu H-B, Lou T-P, Sui Z-T, Zhang Y (2018) Hierarchically nanostructured vanadium nitride microspheres assembled with porous nanosheets fabricated by a template-free route. Ceram Int 44(2):1583-1588

[35] A. Nelkel, The Physics and Chemistry of Carbides; Nitrides and Borides, Kluwer Academic Publishers, Netherlands in: R. Freer (Ed.) (1990) 279-296

[36] Mei A-B, Hellman O, Wireklint N, Schleputz CM, Sangiovanni DG, Alling B, Rockett A, Hultman L, Petrov I, Greene
JE (2015) Dynamic and structural stability of cubic vanadium nitride. Phys Rev B 91(054101):1-11

[37] Isaev EI, Simak S-I, Abrikosov I-A, Ahuja R, Vekilov Y-K, Katsnelson MI, Lichtenstein A-I, Johansson B (2007) Phonon related properties of transition metals, their carbides, and nitrides: a first-principles study. J Appl Phys 101:123519

[38] Forniés E, Galindo R-E, Sánchez O, Albella J (2006) Growth of $\mathrm{CrNx}$ films by DC reactive magnetron sputtering at constant $\mathrm{N}_{2} / \mathrm{Ar}$ gas flow. Surf Coat Technol 200:6047-6053

[39] Li D, Chen J, Zou C, Ma J, Li P, Li Y (2014) Effects of Al concentrations on the microstructure and mechanical properties of Ti-Al-N films deposited by RF-ICPIS enhanced magnetron sputtering. J Alloy Compd 609:239-243

[40] Aissani L, Alhussein A, Nouveau C, Radjehi L, Lakdhar I, Zgheib E (2019) Evolution of microstructure, mechanical and tribological properties of vanadium carbonitride coatings sputtered at different nitrogen partial pressures. Surf Coat Technol 374:531-540

[41] Bouaouina B, Besnard A, Abaidia S-E, Airoudj A, Bensouici F (2018) Correlation between mechanical and microstructural properties of molybdenum nitride thin films deposited on silicon by reactive R.F. magnetron discharge. Surf Coat Technol 333:32-38

[42] Detor A-J, Hodge A-M, Chason E, Wang Y, Xu H, Conyers M, Nikroo A, Hamza A (2009) Stress and microstructure evolution in thick sputtered films. Acta Mater 57:2055-2065

[43] Schulz U, Terry SG, Levi G (2003) Microstructure and texture of EB-PVD TBCs grown under different rotation modes. Mater Sci Eng A 360:319-329

[44] Singh J, Wolfe DE, Singh J (2002) Architecture of thermal barrier coatings produced by electron beam-physical vapor deposition (EB-PVD). J Mater Sci 37:3261-3267. https://d oi.org/10.1023/A:1016187101616

[45] Korneev P-V-K, Pierson J-F, Petrzhik M-I, Alnot M, Levashov E-A, Shtansky D-V (2009) Effect of nitrogen partial pressure on the structure, physical and mechanical properties of $\mathrm{CrB}_{2}$ and $\mathrm{Cr}-\mathrm{B}-\mathrm{N}$ films. Thin Solid Films 517:2675-2680

[46] Lv Y, Ji L, Liu X, Li H, Zhou H (2012) Influence of substrate bias voltage on structure and properties of the CrAlN films deposited by unbalanced magnetron sputtering. Appl Phys Lett 258:3864-3870

[47] Puneet C, Valleti K, Gopal AV, Joshi SV (2018) CrAlSiN nanocomposite thin films for high-speed machining applications. Mater Manuf Process 33(4):371-377

[48] Aissani L, Alhussein A, Ayad A, Nouveau C, Zgheib E, Belgroune A, Zaabat M, Barille R (2021) Relationship between structure, surface topography and tribo-mechanical 
behavior of Ti-N thin films elaborated at different N2 flow rates. Thin Solid Films 724:138598

[49] Aissani L, Alhussein A, Belgroune A, Nouveau C, Zgheib E, Barille R, Montagne A (2021) Effect of carbon content on structural, mechanical and tribological properties of $\mathrm{Cr}-\mathrm{V}-\mathrm{C}$ N coatings. Thin Solid Films 732:138782

[50] Zhang S, Yan F, Yang Y, Yan M, Zhang Y, Guo J, Li H (2019) Effects of sputtering gas on microstructure and tribological properties of titanium nitride films. Appl Surf Sci 488:61-69
[51] Mu Y, Liu M, Zhao Y (2016) Carbon doping to improve the high temperature tribological properties of $\mathrm{VN}$ coating. Tribol Int 97:327-336

[52] M.-H. Staia, A. Trocelis, A. Zairi, M. Suarez, E. S. PuchiCabrera, A. Iost, A. Montagne, Assessment of the mechanical and tribological performance of a ZrN PVD coating, Surf. Eng.(2017) 491-500

Publisher's Note Springer Nature remains neutral with regard to jurisdictional claims in published maps and institutional affiliations. 